\title{
PERBEDAAN ANTARA MEDIA KONVENSIONAL DAN VIDEO TUTORIAL DALAM MENGGAMBAR BENTUK DI SMA NEGERI 1 KUTALIMBARU
}

\author{
Rika Sulngam Litduitna ${ }^{1 *}$, Nelson Tarigan ${ }^{2 *}$, Khae rul Saleh $^{3 *}$ Mus lim$^{4 *}$ \\ Program Studi Pendidikan Seni Rupa Jurusan Seni Rupa Fakultas Bahasa dan Seni \\ Universitas Negeri Medan \\ Jl. Willem Iskandar Pasar V Medan Estate, Kec, Percut Sei Tuan, Kab. Deli Serdang, Kode Pos 20371 \\ Sumatera Utara. Indonesia \\ Email: rikasulngamlitduitna@gmail.com
}

\begin{abstract}
Abstrak
Penelitian ini bertujuan untuk mengetahui perbedaan hasil menggambar bentuk siswa dengan menggunakan media pembelajaran Konvensional dan media pembelajaran Video Tutorial. Populasi dalam penelitian ini adalah seluruh karya siswa kelas X SMA Negeri 1 Kutalimbaru berjumlah 261 karya. Pengambilan sampel menggunakan teknik cluster random sampling, diperoleh sampel penelitian yaitu kelas X MIA-1 sebanyak 36 sis wa. Pada Kelas X MIA-1 ini diberi dua tahap tindakan yaitu pengambilan sampel awal dengan proses belajar-mengajar menggunakan media pembelajaran konvensional. Kemudian setelah itu dilakukan pengambilan sampel yang kedua dengan proses belajar mengajar menggunakan media video tutorial. Metode pengumpulan data yang digunakan antara lain metode dokumentasi, observasi dan tes. Penelitian ini termasuk jen is penelitian kuantitatif dengan desain penelitian eksperimen semu (Quasi-Eksperimen Design). Berdasarkan hasil penelitian diperoleh rata-rata nilaites pertama sebesar 71,43 dan nilai tes kedua 82,74 . Hasil uji perbedaan ratarata menunjukkan bahwa rata-ratanilai kedua lebih baik dari pada nilai pertama. Berdas arkan hasil uji hipotesis dengan signifikansi $\alpha=0,5$ dengan dk 70 didapat $t_{\text {tabel }}=1,6669$. Jadi hasil uji hipotesis diperoleh $t_{\text {hitung }} 5,52>t_{\text {tabel }} 1,66669$. Jadi $\mathrm{H}_{\mathrm{a}}$ diterima sekaligus ditolak $\mathrm{H}_{0}$ kemudian kesimpulannya adalah terdapat perbedaan yang signifikan pada hasil karya menggambar bentuk dengan media pembelajaran Video Tutorial sis wa SMA Negeri 1 Kutalimbaru.
\end{abstract}

Kata Kunci: perbedaan,konvensional, video tutorial, Kutalimbaru.

\begin{abstract}
This research is to determine the differences of student't drawing results using conventional learning media and video tutorial learning media. The population of this research wereall students of class X of SMA Negeri 1 Kutalimbaru totaling 261 works. The Sampling using cluster random sampling technique, obtained research samples namely class X MIA-1 as many as 36 students. For Class X MIA-1 was giving two stages of action, namely initial sampling with the teaching-learning process using conventional learning media. Then after that the second sample was taken with the teaching and learning process using video tutorial media. Data collection methods used include documentation, observation and test methods. This research is a quantitative research with quasi-experimental design. Based on the results of the study, the average value of the first test was 71.43 and the second test score was 82.74. The results of the average difference test show that the average of the second value is better than the first value. Based on the results of hypothesis testing with significance $\alpha=0.5$ with $70 \mathrm{~d}$ obtained table $=1.6669$. So the hypothesis test results obtained t count 5.52 > t table 1.66669. So Ha was accepted and rejected by $\mathrm{HO}$ then the conclusion was that there was a significant difference in the work of drawing shapes with the learning media for Video Tutorials at SMA Negeri 1 Kutalimbaru.
\end{abstract}

Keywords: difference, konventional, tutorial video, Kutalimbaru.

\section{PENDAHULUAN}

Pendidikan merupakan salah satu cara untuk mewariskan nilai-nilai kepada generasi yang akan datang. Nilai-nilai tersebut dapat disalurkan melalui proses belajar, karena belajar merupakan suatu proses yang kompleks yang terjadi seumurhidup. Pendidikan merupakan salah satu programpemerintah yang hingga kini masih terus dikembangkan demi penyempumaan pendidikan baik dari segi kurikulum, metode, maupun media pengajaran yang bertujuan membentuk anak didik yang berkualitas, kreatif dan mengikuti perkembangan Iptek.

Dalam era globalisasi saat ini media pembelajaran sangat beragam, seiring dengan perkembangan ilmu pengetahuan dan teknologi. Lembaga pendidikan 


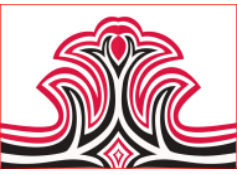

seperti sekolah di tuntut untuk melakukan inovasiinovasi baru terhadap media pembelajaran yang digunakan sehingga tidak tertinggal oleh kemajuan teknologi yang ada. Peran guru dalam inovasi dan pengembangan media pembelajaran sangatlah penting karena guru berperan dalam membangkitkat semangat/minat siswa proses belajar meng ajar dikelas. Maka dari itu mutu dan keprofesionalan guru dapat dilihat. Sejauh mana kemampuan guru dalam pengadaan atau penyediaan dan penguasaan media pembelajaran tersebut.

Penggunaan media pembelajaran video tutorial dapat mempermudah sis wa yang keting galan atau kesulitan s aat guru menerangkan pola dasar menggambar bentuk, karena video tutorial dapat diputar berkali-kali sehingga mempermudah kerja guru tanpa harus mengulang mendemonstrasikan di papan tulis berkalikali. Meskipun penggunaan video tutorial pada s aat ini dianggap sebagai metode yang mampu meningkatkan hasil belajar terutama dalam belajar mandiri. Penggunaan media video tutorial ini masih kurang dipergunakan oleh guru-guru di daerah termasuk di SMA Negeri 1 Kutalimbaru hal ini sesuai dengan pengamatan peneliti.

\section{KAJIAN TEORI}

\section{Perbedaan}

Dalam Kamus Besar Bahasa Indonesia (2011:115) beda adalah "suatu yang menjadikan berlainan (tidak sama),selisih" . Perbedaan atau kesenjangan ini juga terdapat pada hasil belajar siswa. Hasil belajar siswa berbeda-beda, karena setiap siswa memiliki faktorfaktor berbeda yang mempengaruhi hasil belajar. Perbedaan dimaksud dalam penelitian ini adalah hasil kemampuan menggambar bentuk saat menggunakan metode konvensional dan menggunakan metode video tutorial. Hasil kemampuan menggambar tersebut dinyatakan dalam bentuk perolehan nilai karya yang diperoleh siswa.

\section{Pengertian Menggambar Bentuk}

Margono, dkk (2010: 20) bahwa "Menggambar bentuk merupakan cara menggambar dengan meniru objek dengan mengutamakan kemiripan". Mesra, (2014:7) "Menggambar bentuk adalah suatu kegiatan memindahkan objek model yang dilihat lansung, ke atas bidang gambar dengan lebih mengutamakan kemiripan terhadap model tersebut". Nainggolan (2018: 214) menyatakan menggambar merupakan keterampilan yang bisa dipelajari oleh setiap orang, terutama yang mempunyai minat menggambar dengan cara memindahkan objek yang berupa (barang, orang, binatang, tumbung-tumbuhan, dan lain sebagainya) ke
Gorga : Jurnal Seni Rupa

Volume 09 Nomor 01 Januari-Juni 2020

p-ISSN: 2301-5942 | e-ISSN: 2580-2380

atas bidang datar. Di sini penekanan gambar bentuk lebih ke bentuk buah-buahan, namun sebenamya yang menjadi objek atau ide dalammembuat gambar bentuk bis a dengan bentuk-bentuk lain yang lebih ditekankan pada local genius disuatu daerah, misalnya etnik di Sumatera Utara, "virtual" of a region (ethnicity) is a policy to present artwork, which is expected to be able to counter or at least be a companion of popular art products that contain foreign cultural value elements ("virtual suatu daerah (etnis) adalah kebijakan untuk menyajikan karya seni, yang diharapkan mampu membalas atau setidaknya jadilah pendamping produk seni popular yang mengandung nilai-nilai budaya asing), (Zulkifli, 2019: 183).

Berdasarkan beberapa pendapat di atas dapat dis impulkan bahwa menggambar bentuk adalah proses menggambar diawali dengan menata objek yang digambar, melihat dan memperhatikan objek secara langsung kemudian menuangkannya keatas bidang gambar dan mengutamakan kemiripan terhadap model.

\section{Teknik Menggambar Bentuk}

Ada beberapa teknik yang dapat di terapkan dalam menggambar bentuk seperti teknik arsir, blok, dusel, pointilis, aquarel, plakat. Dalam penelitian ini teknik yang digunakan adalah teknik arsir menggunakan pensil. Dalam gambar bentuk teknik ars ir adalah suatu cara untuk menimbukan kesan gelap-terang dan juga menghasilkan bentuk nyata dari objek yang digambar. Semakin rapat garis yang diterapkan pada suatu bidang akan meberi kes an semakin gelap. Sebaliknya semakin jarang garis-garis yang digoreskan pada suatu bidang akan memberi kesan semakin terang.

\section{Prinsip Menggambar Bentuk 1). Komposisi}

Susanto (2011:226) mengatakan "Komposisi (dinamis) kombinasi berbagai elemen gambar atau karya untuk mencapai kes esuaian atau integrasi antara warna, garis, bidang, dan unsur-unsur seni yang lain untuk mencapai susunan yang dinamis, termasuk tercapainya proporsi yang menarik serta artis tik". Senada deng an pendapat Susanto, Pamungkas (2017 : 162) mengatakan "Komposisi adalah "elemen-elemen yang terdapat di dalam karya seni yang menjadi karya seni yang utuh, seperti garis, warna, dan sebagainya”. Komposisi merupakan suatu susunan dari beberapa unsur secara seimbang dan serasi atau harmonis (Mesra dalam Siregar 2020: 96).

Berdas arkan pendapat di atas dapat disimpulkan bahwa pengertian komposisi adalah penyusunan dari unsurunsur rupa yang mengacu ke tata artis tik suatu karya 


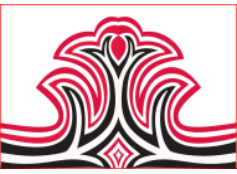

agar tercapainya penyusunan yang seimbang dan dinamis

\section{2). Proporsi}

Susanto (2011:320) mengatakan “Proporsi merupakan hubung an ukuran antar bagian dan bagian, serta bagian dan kesatuan/keseluruhannya. Proporsi berhubungan erat dengan balance (keseimbangan), rhythm (irama, harmoni) dan unity". Pendapat yang sama juga dijelaskan Kartika (2017:61) "Proporsi mengacu kepada hubungan antara bagian dari suatu desain dan hubungan antara bagian dengan keseluruhan. Jadi proporsi tergantung kepada tipe dan besarnya bidang, warna, garis, dan tekstur dalam beberapa area".

Senada dengan pendapat di atas menurut Picard (2016:27) "To scale your drawing and establish proportions in correct relationship to one another, select a clear and easy portion of the subject to use as a unitofmeasurement for reference againstother parts of the scene" yang artinya "Untuk memberi skala gambar Anda dan menetapkan proporsi dalam hubung an yang benar satu sama lain, pilih bagian yang jelas dan mudah untuk digunakan sebagai rekomendasi pengukur antar keadaan".

Berdasarkan beberapa pendapat di atas maka penulis menarik kesimpulan proporsi adalah perbandingan bagian per bagian atau bagian dengan keselumhan objek. Proporsi menggambarkan keseimbangan dua objek atau lebih dalam berbagai hal seperti bentuk, keindahan, ukuran, bahan, dan lainnya. Dalam menggambar bentuk perbandingan ukuran antara bagian per bagian sangatlah perlu diperhatikan. Misalkan perbandingan antara buah rambutan dengan buah semangka, ukuran buah rambutan tidak akan mungkin lebih besar dari pada buah semangka.

\section{3). Perspektif}

Menurut Apriyatno (2013:22) "Perspektif atau sudut pandang adalah teknik atau metode untuk menggambar objek-objek berupa benda, ruang (interior), dan lingkungan (eksterior) yang ukurannya lebih besar dari manusia”. Purnomo (2007:2) dalam Jurnal Ilmu dan Seni, ISI Surakarta GELAR Vol. 5, No.1, Juli menuliskan

"Kata perspektif berasal dari bahasa Itali yaitu prospetiva yang memiliki arti gambar pandangan (Yohanes Suprayono, 1982:7). Dalam gambar kerja yang berkaitan dengan sebuah perencanaan dan perancangan, perspektif biasanya digunakan untuk menjelaskan maksud rancangan secara tiga dimensi pada bidang datar dalam bentuk gambar perspektif".
Gorga : Jurnal Seni Rupa

Volume 09 Nomor 01 Januari-Juni 2020

p-ISSN: 2301-5942 | e-ISSN: 2580-2380

Sederhananya perspektif adalah cara melukiskan suatu benda pada permukaan yang mendatar sebagaimana yang terlihat oleh mata degan tiga dimensi (panjang, lebar dan tingginya). Dalam menggambar bentuk pers pektif sangat perlu diperhatikan oleh sipenggambar karena akan berpengaruh pada hasil karya sipenggambar itu sendiri.

\section{4). Gelap Terang}

Gelap dan terang menurut Bastomi (1992:59)"Dalam seni rupa bagian benda yang kena cahaya dinyatakan terang, sedangkan bagian yang tidak terkena cahaya dinyatakan gelap. Bagian yang terang disebut bagian yang positif, bagian yang gelap disebut bagian yang negatif. Bagian benda yang tidak terkena cahaya langsung adalah bagian benda yang mendapat cahaya pantul dari bagian benda yang lain. Bagian itu disebut bayangan (shadow)".

Dalam menggambar bentuk ini peran bayang-bayang sangat membantu memunculkan kesan 3 dimensi (realis).Oleh karena itu bayangan-bayangan harus ada di dalam menggambar bentuk dengan menggunakan teknik arsir. Seperti pendapat Tizon (2007: 66) dalam art of sketching "shadows are used to give a threedimensional aspect to shapes. In is important to emphasize the light effect observed, even to exaggerate them". Yang memiliki arti "bayangan digunakan untuk memberikan aspek tiga dimensi pada bentuk. Penting untuk menekankan pengamatan terhadap efek cahaya, bahkan untuk dilebih-lebihkan".

Berdasarkan pendapat tersebut gelap terang adalah bagian tergelap dan bagian terang sebuah benda yang terkena cahaya. Dalam menggambar bentuk gelap terang sangat menentukan hasil daripada karya, kesan gelap dan terang mempengaruhi tingkat ke-realis an dari objek yang digambar.

\section{Alat dan Bahan Menggambar Bentuk}

Beberapa alat dan bahan yang digunakan dalam menggambar bentuk adalah pensil, sharpener atau pengraut pensil, karet penghapus, kertas.

\section{Langkah-Langkah Menggambar Bentuk}

Langkah-langkah dalam mengg ambar bentuk melalui beberapa step yang peratama adalah memilih objek model , menata objek model, mensket objek gambar, mengarsir objek gambar dan tahap akhir adalah penyelesaian gambar (finishing).

\section{Hasil Karya Menggambar Bentuk}

Dalam penelitian ini sebagai pokok utama dalam pembahasan adalah menggambar bentuk. Menggambar 
bentuk y ang dimaks ud merupakan proses pembelajaran dalam materi seni budaya (menggambar) yang diselenggarakan di sekolah terutama kelas X. Pada proses pembelajaran menggambar bentuk yang berlangsung guru masih menggunakan media pembelajaran konvensional, yaitu hanya dengan menggunakan buku paket sebagai pedoman. Media yang digunakan oleh guru adalah media seadanya seperti spidol dan papan tulis. Siswa disajikan beberapa objek model yang akan digambar.

Pengungkapan gambar yang ditugaskan oleh guru dilakukan dengan teknik arsir pensil. Pembelajaran yang berlangsung diawali dengan penjelasan guru tentang objek sebagaitema pokok dalammenggambar kemudian dijelaskan proporsi gambar termasuk proporsi ukuran objek dengan kertas gambar. Susunan ataupun komposisi pada objekjuga ditekankan kepada siswa agar dapat lebih mempertimbangkan keseimbangan dalam karyanya.

Kemudian untuk mengungkapkan dimensi atau kesan agar tampak benda mempunyai kedalaman maka gunu juga menjelas kan arah dan besarnya sinar yang datang menimpa objek sehing gatampak bahwa benda tersebut memiliki bagian yang gelap dan bagian yang terang dan bayang-bayang. Menerapkan bagian yang gelap dan terang serta bayang-bayang guru membimbing siswa dalam teknis penggunaan pensil agar sis wa dapat lebih terarah menempatkan pada bagian mana arsiran yang mendapatkan tekanan sedikit lebih lembut dan pada bagian mana arsiran y ang mendapat tekanan lebih kuat. Secara dimensional efek terang gelap pada objek merupakan upaya mengenalkan wujud tiga dimensi dan secara teknikal efek keras lembutnya tekanan pensil mewujdkan kesan ruang dan kedalaman kepada objek untuk menghadirkan visualis asi tiga dimensi di atas kertas gambar.

Inilah proses pemebelajaran yang diterapkan pada menggambar bentuk kelas X SMA Negeri 1 Kutalimbaru. Proses pembelajaran dengan media pembelajaran konvensional ini dinilai oleh peneliti masih sangat kurang mendukung keaktifan dan kreatifitasan siswa. Hal ini dapat dilihat darinilai hasil kemampuan menggambar bentuk siswa yang belum memuaskan. Dengan menggunakan media pembelajaran video tutorial diharapkan terdapat perbedan pada hasil karya menggambar bentuk siswa SMA Negeri 1 Kutalimbaru, khususnya kelas X.

\section{Media Pembelajaran \\ 1). Media}

Media merupakan kata yang tidak asing lagi didegar sekarang ini "kata media berasal daribahasa Latin dan
Gorga : Jurnal Seni Rupa

Volume 09 Nomor 01 Januari-Juni 2020

p-ISSN: 2301-5942 | e-ISSN: 2580-2380

merupakan bentuk jamak darikata medium yang secara harfiah berartiperantara atau peng antar. Medòe adalah perantara atau pengantar pesan dari pengirim ke penerima pesan". (Sadiman, dkk 2009: 6). Menurut Kamus Besar Bahasa Indonesia media adalah "alat atau (sarana) komunikasi seperti koran, majalah, radio, televisi, film, poster, dan spanduk; yang terletak diantara dua pihak (orang, golongan, dan sebagainya);prantara; penghubung". Heinich, dkk dalam Arsyad (2017 : 3) mengemukakan "istilah media, sebagai prantara yang mengantar informasi antara sumber dan penerima. Jadi televisi, film, foto, radio, rekaman audio, gambar yag diperoyeksikan, bahan-bahan cetakan dan sejenisnya adalah media komunikasi. Apabila media bertujuan instruksional atau mengandung maksud-maksud pengajaran maka media itu disebut pembelajaran". Seiring dengan paparan tersebut di atas Kartono (2020 : 128) mengatakan media merupakan segala hal yang dapat digunakan untuk menyalurkan pesan, informasi, knowledge, dan lain sebagainya, yang disampaikan oleh seorang dosen atau guru kepada mahasiswa atau siswa dengan inovasi dan penyampaian yang lebih menarik, sehingga dapat meningkatkan stimulus keinginan untuk belajar bagi peserta didik, baik itu mahas is wa ataupun siswa.

Sejalan dengan pendapat tersebut, Hamidjojo dan Latuheru (1993) mengatakan "media sebagai semua bentuk perantara yang digunakan oleh manusia untuk menyampaikan atau menyebar ide, gagasan, atau pendapat sehingga ide, gagasan atau pendapat yang dikemukakan itu s ampai kepada penerima yang dituju".

Dari beberapa pendapat tersebut dapat disimpulkan bahwa media adalah perantara, sarana, alat atau wadah yang dapat berisi penyampaian segala bentuk informasi dan pengetahuan. Media adalah bagian yang tidak terpisahkan dari proses belajar mengajar demi tercapainya tujuan pendidikan pada umunya dan tujuan pembelajaran di sekolah pada khusunya.

\section{2). Media Pembelajaran}

Menurut Gerlach \& Ely (1971) dalamArs yad (2017:3) mengatakan bahwa media apabila dipahami secara garis besar adalah manusia, materi, atau kejadian yang membangun kondisi yang membuat siswa mampu memperoleh pengetahuan, ktrampilan, atau sikap". Menurut Latuheru dalam Suryani (2012: 137), menyatakan bahwa media pembelajaran adaah bahan, alat, atau teknik yang digunakan dalam kegiatan belajar-mengajar dengan maksud agar proses interaksi komunikasi pendidikan antara guru dan siswa dapat berlangsung secara tepat guna dan berdaya guna". 
Arsyad(2017:3) media pembalajaran adalah "alat yang menyampaikan atau mengantarkan pesan-pesan pembelajaran".

Dari beberapa pendapat diatas dapat disimpulkan bahwa media pembelajaran adalah alat, bahan, dan wahana yang dapat menyalurkan (meyampaikan) pesan dan inforamasi kepada siswa untuk memperoleh pengetahuan, ketrampilan dan dapat merangsang pikiran, perasan, juga kemauan peserta didik dalam belajar sehing ga tercapainya tujuan pembalajaran yang diinginkan.

\section{3). Fungsi Media Pembelajaran}

Sadiman, dkk (2009:17) menyampaikan fungsi media pendidikan secara umum, adalah sebagai berikut:

“1) memperjelas penyajian pesan agar tidak terlalu bersifat verbalistis, 2) mengatasi keterbatasan ruang, waktu, dan daya indra, mis al objek yang terlalu besar untuk dibawa ke kelas dapat diganti dengan gambar, slide,dsb. Peristiwa yang terjadi di masa lalu bida ditampilkan lagi lewat film, video, foto atau film bingkai, 3) meningkatkan kegairahan belajar, memungkinkan siswa belajar sendiri berdasarkan minat dan kemampuannya, dan mengatasi sikap pasif siswa, 4) memberikan rangsangan yang sama, dapat menyamakan pengalaman dan persepsi sis wa terhadap isi pelajaran".

Dari pendapat diatas dapat disimpulkan bahwa ada beberapa macamfungsi dari media pembelajaran yang dapat membantu siswa dalam merespon materi pembelajaran, membangkitkan minat belajar siswa, dan memudahkan sis wa memahami isi materi sehingga dapat membantu siswa dalam proses belajar mengajar.

\section{Media Pembelajaran Video Tutorial}

Menurut Arsyad, (2009 : 94) menerangkan bahwa media audio visual merupakan media yang menggabungkan penggunaan gambar dan suara yang memerlukan pekerjaan tambahan untuk memproduksinya seperti penulisan naskah dan stroryboard. Daryanto (2011:51) menyatakan bahwa "tutorial merupakan multimedia pembelajaran yang dalam penyampaian materinya dilakukan secara tutorial, s ebagaimana layaknya tutorialy ang dilakukan oleh guru atau instruktr, informasi yang berisi sesuatu konsep disajikan dengan teks, dan gambar, baik diam maupun bergerak dan grafik".

Menggambar bentuk pada umumnya dapat dilakukan dengan demonstrasi langsung didepan kelas, akan tetapi akan lebih bervariatif dan lebih fleksibel dalam belajar apabila pembelajaran dikembangkan lebih luas
Gorga : Jurnal Seni Rupa

Volume 09 Nomor 01 Januari-Juni 2020

p-ISSN: 2301-5942 | e-ISSN: 2580-2380

dan menarik. Penggunaan media video tutorial adalah salah satu solusi dalam mata pelajaran seni rupa. Pembelajaran melalui media video tutorial diharapkan dapat mengembangkan potensi pesera didik menjadi lebih baik sebagai upaya dalam meningkatkan kemampuan diri sis wa dalam pelajaran seni rupa.

Dapat disimpulkan penggunaan media video tutorial sangat berpengaruh terhadap efesiensi pembelajaran dan dapat mengatasi keterbatasan ruang, waktu dan daya indra.

\section{Hipotes is Penelitian}

Hipotesis penelitian dilakukan dengan memebandingkan sepasang hipotesis statistik yang dapat dinyatakan sebagai berikut:

$$
\begin{aligned}
& H_{0}: \mu_{1}=\mu_{2} \\
& H_{a}: \mu_{1} \neq \mu_{2}
\end{aligned}
$$

Dengan kalimat dapat dituliskan sebagai berikut:

$H_{0} \quad=$ Diduga tidak terdapat perbedaan yang signifikan antara penggunaan media pembelajaran video tutorial terhadap hasil belajar menggambar bentuk pada siswa kelas X MIA 1 SMA Negeri 1 Kutalimbaru.

$H_{a}=$ Diduga terdapat perbedaan antara penggunaan media pembelajaran video tutorial terhadap hasil belajar menggambar bentuk pada siswa kelas X MIA1 SMA Negeri 1 Kutalimbaru.

\section{METODE PENELITIAN}

Penelitian ini dilaksanakan di SMA Negeri 1 Kutalimbaru Jalan. Pendidikan Pasar IV, Suka Rende, Kec. Kutalimbaru, Kab. Deli Serdang. Jumlah populasi 261 dengan 36 sampel siswa kelas X. Metode yang digunakan dalam penelitian ini adalah kuantitatif. Teknik pengumpulan data yang digunakan tes, dokumentasi, observasi. Instrumen peneltian yang digunkan yaitu buku catatan, kamera dan media pembelaaran video tutorial. Teknik analis is data yang digunakan yaitu uji persyaratan analisis menggunakan uji t (uji beda). 


\section{HASIL DAN PEMBAHASAN}

\section{Hasil}

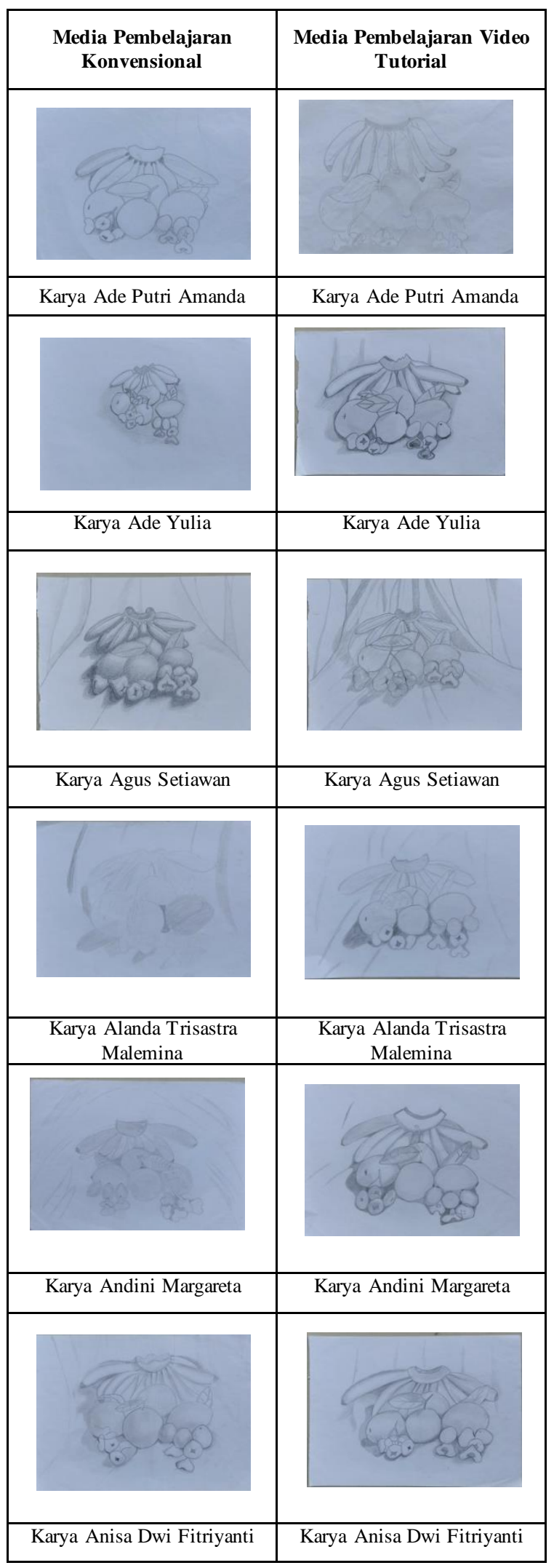

Gorga : Jurnal Seni Rupa

Volume 09 Nomor 01 Januari-Juni 2020 p-ISSN: 2301-5942 | e-ISSN: 2580-2380

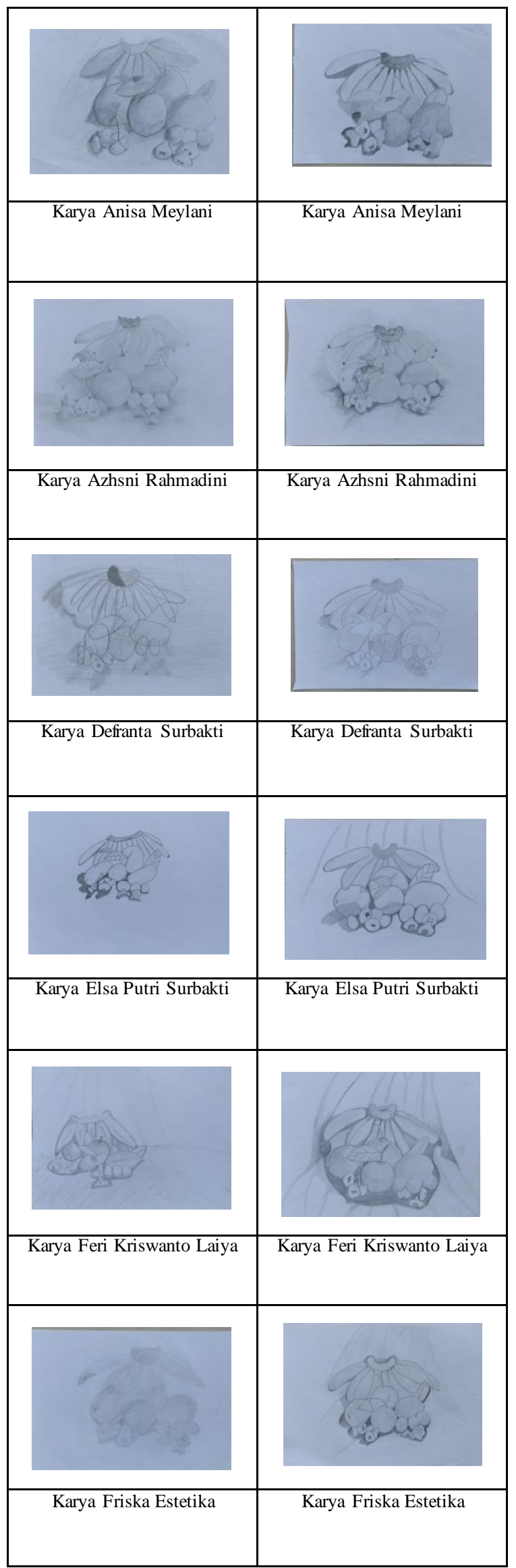




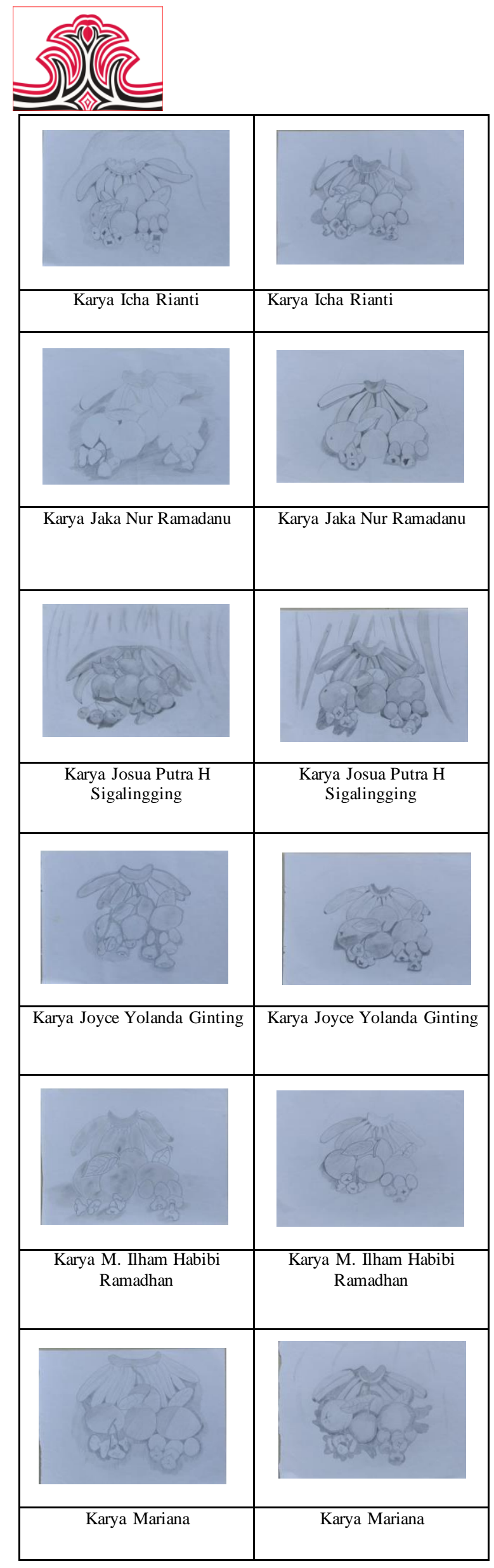

Gorga : Jurnal Seni Rupa

Volume 09 Nomor 01 Januari-Juni 2020

p-ISSN: 2301-5942 | e-ISSN: 2580-2380

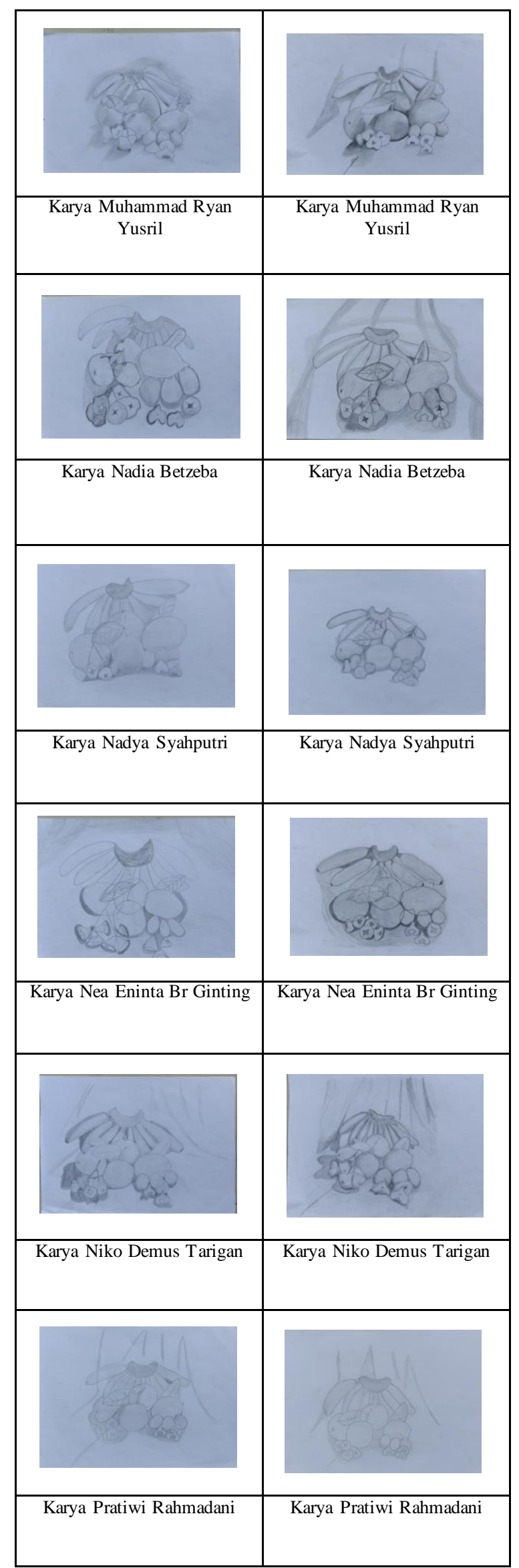




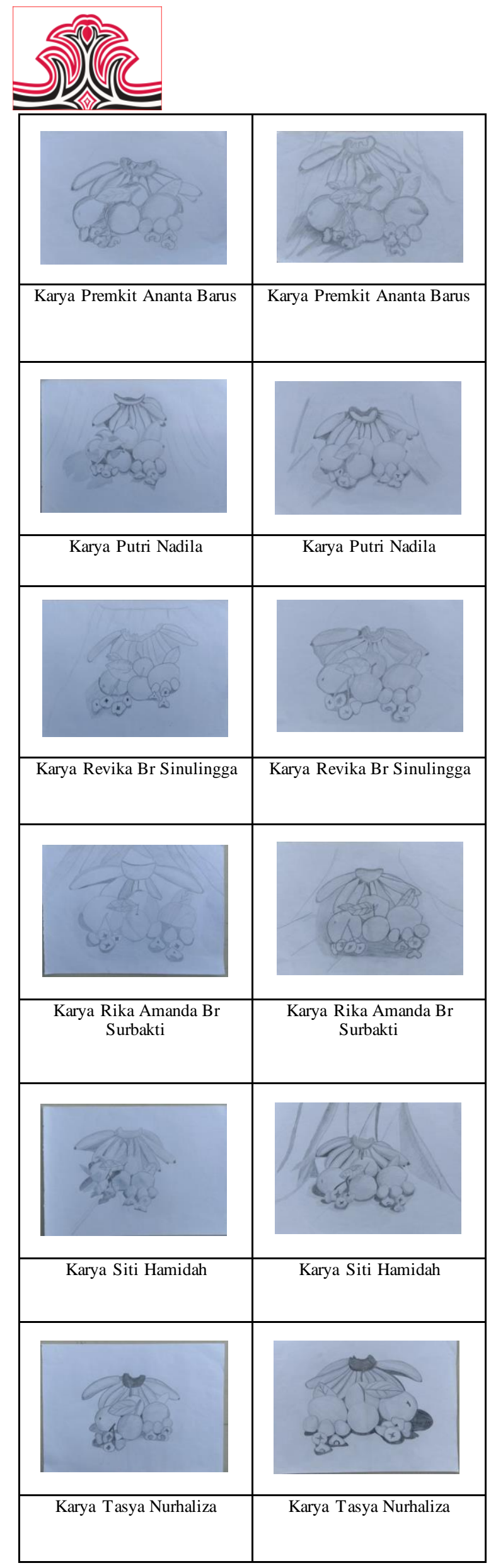

Gorga : Jurnal Seni Rupa

Volume 09 Nomor 01 Januari-Juni 2020 p-ISSN: 2301-5942 | e-ISSN: 2580-2380

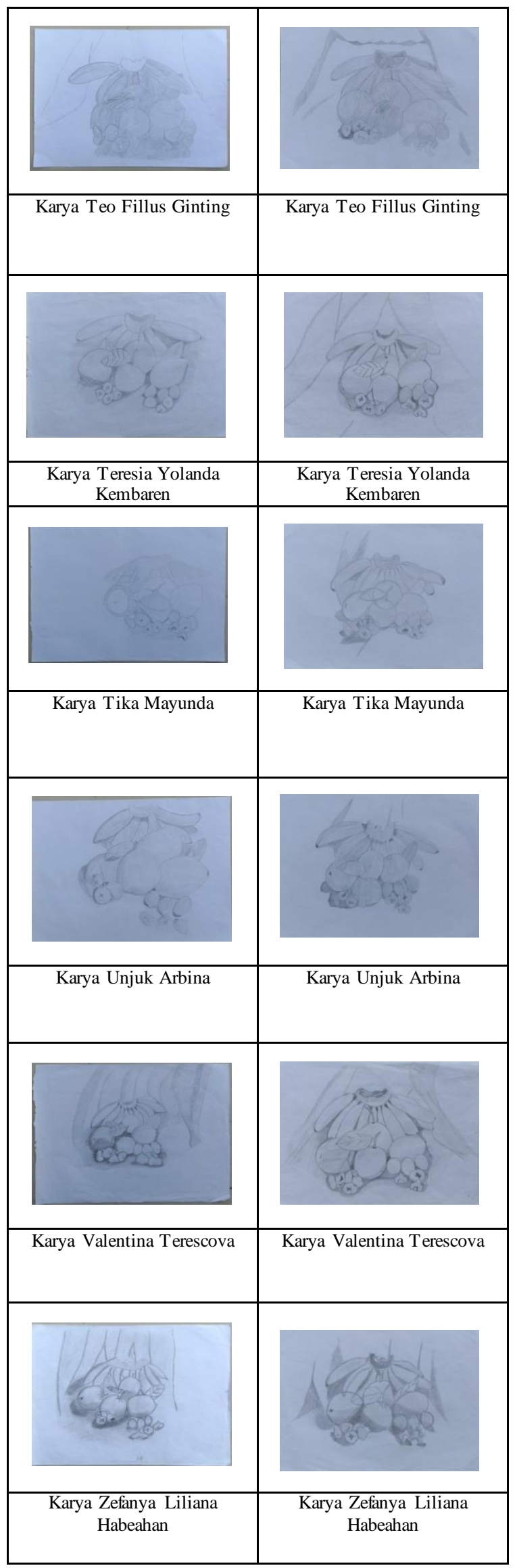




\section{Pembahas an}

\section{1). Uji Normalitas}

Hasil perhitungan uji normalitas nilai hasil belajar sis wa pada kelas ekperimen pada taraf signifikansi $\alpha=$ 0,05 dengan jumlah sampel $(\mathrm{N}=36)$ diperoleh Lhitung $<$ Ltabel. Demikian nyata bahwa pengujian kelas ekperimen yang menggunakan media pembelajaran video tutorial berasal dari populasi yang berdis tribusi normal.

Hasil perhitungan uji normalitas nilai hasil belajar sis wa pada kelas kontrol pada taraf signifikansi $\alpha=0,05$ dengan jumlah sampel $(\mathrm{N}=36)$ diperoleh Lhitung < Ltabel. Demikian nyata bahwa pengujian kelas kontrol yang menggunakan media pembelajaran konvensional berasal dari populasi yang berdistribusi normal.

Tabel 1. Kelas Eksperimen dan Kelas Kontrol

\begin{tabular}{|l|l|l|l|l|}
\hline \multirow{2}{*}{ No. } & \multirow{2}{*}{ Kelas } & \multicolumn{3}{|l|}{} \\
\cline { 3 - 5 } & & $\mathrm{L}_{\text {hitung }}$ & $\mathrm{L}_{\text {tabel }}$ & Status \\
\hline 1 & Eksperimen & 0,0752 & 0,147 & Normal \\
\hline 2 & & & & \\
\hline & & 0,0689 & 0,147 & Normal \\
\hline
\end{tabular}

\section{2) Hasil Uji Homogenitas}

Uji homogenitas digunakan untuk mengetahui apakah populasi beras al dalam homogenitas yang sama atau tidak. Uji homogenitas menggunakan teknik uji Bartlett. Diperolah $X_{\text {hitung }}^{2}=0,6769$ dan $X_{\text {tabel }}^{2}=3,841$ . Sesuai dengan kriteria pengujian homogenitas data dengan teknik uji Bartlett, maka disimpulkan bahwa data has il penilitian berasal dari s ampel yang homogen denga $X_{\text {hitung }}^{2}<X_{\text {tabel }}^{2}$ yaitu $0,6769<3,841$.

\section{3) Uji Hipotesis}

Setelah melakukan uji persyaratan analis is data yaitu uji normalitas dan uji homogenitas telah diketahui bahwa kedua s ampel berasal dari populasi yang normal dan homogen. Dengan demikian dapat dilakukan pengujian hipotesis statis tik dengan ujit dengan tujuan mengetahui ada tidaknya pengaruh dalam penerapan penggunaan media pembelajara video tutorial pada hasil karya menggambar bentuk siswa SMA Negen 1 Kutalimbaru tahun ajaran 2019/2020.

Dari data perhitungan pada lampiran diperoleh bahwa $\mathrm{t}_{\text {hitung }}=5,52$. Harga $\mathrm{t}_{\text {tabel }}$ dengan $\mathrm{dk}=(36+36)-2=70$ dan signifikasi $\alpha=0,05$ adalah 1,6669. Adapun kriteria penerimaan dan penolakan hipotesis yaitu:

Jika hasil $t_{\text {hitung }}<t_{\text {tabel }}$, maka $\mathrm{H}_{\mathrm{o}}$ diterima dan tolak $\mathrm{H}_{\mathrm{a}}$, jika hasil $t_{\text {hitung }}>\mathrm{t}_{\text {tabel, }}$, maka $\mathrm{H}_{\mathrm{a}}$ diterima dan tolak $\mathrm{H}_{\mathrm{o}}$. Sesuai dengan kriteria penerimaan dan penolaka hopotesis maka dapat di simpulkan bahwa ada perngaruh atau ada perbedaan yang signifikan dari penerapan media pembelajaran video tutorial temadap hasil menggambar bentuk siswa SMA Negeri 1 Kutalimbaru tahun ajaran 2019/2020.

Tabel 2. Ringkasan Hasil Analisis Uji t

\begin{tabular}{|c|c|c|c|c|}
\hline Sampel & $\begin{array}{c}\text { Rata- } \\
\text { rata }\end{array}$ & $\mathrm{T}_{\text {hitung }}$ & $\mathrm{T}_{\text {tabel }}$ & Simpulan \\
\hline Kelompok & 71,43 & 5,52 & 1,6669 & $\begin{array}{c}\text { Ada } \\
\text { pengaruh }\end{array}$ \\
\hline $\begin{array}{c}\text { Konvensional } \\
\text { Video Tutorial }\end{array}$ & 82,74 & & \\
\hline
\end{tabular}

\section{KESIMPULAN DAN SARAN}

\section{Kesimpulan}

Berdasarkan hasil penelitian yang telah dipaparkan dalambab sebelumn ya, maka dapat diuraikan beberapa simpulan seperti hasil kary a menggambar bentuk siswa kelas X-MIA 1 SMA Negeri 1 Kutalimbaru menggunakan media pembelajaran konvensional memiliki rata-rata : 71,43 dengan nilai terendah 51,67 dan nilai tertinggi 91,33 dengan frekuensi 1. Sedangkan hasil karya menggambar bentuk siswa kelas X-MIA 1 SMA Negeri 1 Kutalimbaru menggunakan media pembelajaran video tutorial memiliki rata-rata :82,74 dengan nilai terendah 63,33 dan nilai tertinggi 96,67 dengan frekunsi 1 .

Terdapat perbedaan nilai yang signifikan dari hasil karya meng gambar bentuk s is wa kelas XMIA-1 SMA Negeri 1 Kutalimbaru dengan menggunakan media pembelajaran konvensional dan media pemebelajaran video tutorial. Hal ini dapat dilihat dari nilai rata-rata yang diperoleh siswa media konvensional sebesar 71,43 dan video tutorial 82,74.

\section{Saran}

Berdasarkan hasil penelitian dan kesimpulan, maka penelitian menyampaikan beberapa saran seperti kepada sekolah untuk melengkapi sarana prasarana sekolah berbasis media elektronik dalam menunjang proses pembelajaran dan kepada pendidikbidang studi Seni Budaya (Seni Rupa) dapat menerapkan media pembelajaran audio visual sebagai alternatif media pembelajaran dikelas dalam meningkatkan minat dan hasil belajar seni rupa.

\section{DAFTAR RUJUKAN}

Apriyatno, Veri. (2013). Cepat dan Mudah Belajar Menggambar dengan Pensil. Jakarta: Kawan Pustaka.

Arsyad, Azhar. (2017). Media

Pembelajaran.Jakarta:Rajawali Pers. 
Bastomi, Suwaji. (1992). Wawasan Seni. Semarang: IKIP Semarang Press.

Daryanto. (2016). Media Pembelajaran. Yogyakarta: Gava Media.

Hamidjojo dan Latuheru, J.D., (1993). Media Pembelajaran Dalam Proses Belajar Mengaar Kini, Ujung Pandang: IKIP Ujung Pandang Pers.

Kartika, dars ono Sony. (2017). Seni RupaModern. Bandung: Rekayasa Sains.

Kartono, G., Mesra, M., \& Azis, A. C. K. (2020). Pengembangan Media Ajar Grafis Komputer Materi WPAP dalam Bentuk E-book dan Video Tutorialbagi Mahasis waSeni Rupa. Gorga: Jurnal Seni Rupa, 9(1), 127-132.

Margono, Try \& Aziz A. (2010). Mari Belajar Seni Rupa:Jakarta.

Mesra. (2014). Gambar Bentuk 1. Medan:Unimed Press.

Nainggolan, M., Silaban, B., \& Azis, A. C. K. (2018). Analisis Karya Gambar Bentuk Siswa Kelas VII SMP Negeri 1 Simangumban Berdasarkan Prinsip-Prinsip Seni Rupa. Gorga: Jurnal Seni Rupa, 7(2), 212-217.

Pamungkas, Aditya Septian.(2017). Menggambar Manual dan Digital Itu Gampang,Kok!.Yogyakarta: Second Hope.

Picard, Alain. (2016). Beginning Drawing. USA: W alter Foster Publis hing.

Purnomo, Agung. (2007). Pres pektif Dalam Seni Lukis Trasisi Indonesia. Gelar, 05(01), 1-14.

Sadiman, Arief S. (2009). Media Pendidikan Pengertian, pengembangan, dan pemanfaatannya. Jakarta:PT RajaGrafindo Persada.

Siregar, N. H., Azis, A. C. K., Mesra, M., \& Mirwa, T. (2020). Analis is Gambar Bentuk Bunga Anggrek dengan Teknik Pointilis Berwarna di SMP Al-Fityan School Medan. Gorga: Jurnal Seni Rupa, 9(1), 94-99.

Suryani, Nunuk dan Leo Agung, (2012), Strategi Belajar Mengajar, Yogyakarta: Ombak

Sus anto, Mikke. (2011). Diksi Rupa. Yogyakarta: Dicti Art Lab.

Tizon, Natalia. (2007). Art of Sketching. New York: Starling Publishing.

W.J.S, Poerwadarminta. (2011). Seri Bahasa Indonesia. Jakarta Timur: Balai Pustaka.

Zulkifli, Z., Sembiring, D., Atmojo, W.T., \& Pasaribu, M. (2019, May). The Ethnicity of Nias in the Creative Exploration of Art Painting of North Sumatera. In 2nd International Conference on Arts and Culture (ICONARC 2018). Atlantis Press. 